\title{
Endoplasmic reticulum stress as target for treatment of hearing loss
}

\author{
Yanfei WANG, Zhigang XU \\ Shandong Provincial Key Laboratory of Animal Cell and Developmental Biology, School of Life Sciences, Shandong University, Qingdao, Shandong \\ 266237, China \\ *Correspondence: xuzg@sdu.edu.cn \\ https://doi.org/10.37175/stemedicine.v1i3.21
}

\begin{abstract}
The endoplasmic reticulum (ER) plays pivotal roles in coordinating protein biosynthesis and processing. Under ER stress, when excessive misfolded or unfolded proteins are accumulated in the ER, the unfolded protein response (UPR) is activated. The UPR blocks global protein synthesis while activates chaperone expression, eventually leading to the alleviation of ER stress. However, prolonged UPR induces cell death. ER stress has been associated with various types of diseases. Recently, increasing evidences suggest that ER stress and UPR are also involved in hearing loss. In the present review, we will discuss the role of ER stress in hereditary hearing loss as well as acquired hearing loss. Moreover, we will discuss the emerging ER stress-based treatment of hearing loss. Further investigations are warranted to understand the mechanisms in detail how ER stress contributes to hearing loss, which will help us develop better ER stress-related treatments.
\end{abstract}

Keywords: ER stress · Unfolded protein response (UPR) · Hearing loss · Inner ear · Cochlea

\section{Introduction}

The endoplasmic reticulum (ER) is a highly dynamic organelle in eukaryotic cells, playing important roles in protein synthesis, processing, folding, and transportation, as well as lipid synthesis and calcium homeostasis. Newly synthesized transmembrane and secretory proteins must be folded and processed in the ER before being targeted to their final destinations. Misfolded proteins will be folded into correct conformations in the ER with the help of chaperon proteins such as binding immunoglobulin protein (BiP)/glucose regulated protein 78 (GRP78) (1). Alternatively, misfolded proteins are subjected to degradation through the proteasome-dependent ERassociated protein degradation (ERAD) pathway (2). Physiological or pathological conditions such as hypoxia, acidosis, or calcium fluxes can disturb ER homeostasis and result in an accumulation of unfolded or misfolded proteins in the ER, commonly referred to as ER stress. To alleviate ER stress, the so-called unfolded protein response (UPR) is activated, which blocks protein synthesis and activates chaperone gene expression (3).

Three main UPR pathways have been identified so

Received: Oct 28, 2019; Accepted: Dec 29, 2019.

(c) The Author(s). 2020 This is an Open Access article distributed under the terms of the Creative Commons License (http://creativecommons.org/licenses/by/4.0/) which permits unrestricted use, distribution, and reproduction in any medium or format, provided the original work is properly cited. far, which are mediated by ER stress sensors that reside on the ER membranes, namely the inositol-requiring enzyme $1 \alpha$ (IRE1 $\alpha)$, the PKR-like ER kinase (PERK), and the activating transcription factor $6 \alpha$ (ATF6 $\alpha$ ) (Figure 1). These sensors are all transmembrane proteins that are normally inactivated by BiP binding at the ER lumen side. Under ER stress, accumulated unfolded proteins sequester BiP from the ER stress sensors and activate UPR through three independent pathways: (i) Upon release from BiP, IRE $1 \alpha$ oligomerizes and transautophosphorylates itself, which then activates its endoribonuclease activity. Activated IRE $1 \alpha$ catalyzes the splicing of $X B P 1$ mRNA into XBP1s that encodes an active transcription factor. XBP1s then enters the nucleus and activates gene expression involved in ER membrane biogenesis and protein folding. (ii) Similar to IRE $1 \alpha$, PERK obtains its kinase activity through oligomerization and trans-autophosphorylation after being released from BiP. After activation, PERK phosphorylates the $\alpha$ subunit of eukaryotic translational initiation factor $2 \alpha$ (eIF2 $\alpha$ ) on Ser51. Phosphorylated eIF2 $\alpha$ attenuates global protein synthesis to reduce the ER protein-folding load. Meanwhile, it enhances the translation of certain proteins such as activating transcription factor 4 (ATF4). ATF4 enters the nucleus and induces gene expression that are involved in ER function and reactive oxygen species (ROS) production. (iii) Upon release from BiP, ATF6 $\alpha$ translocates from the ER to the Golgi apparatus. At the 
Golgi, site-1 protease (S1P) and site-2 protease (S2P) sequentially cleaves ATF6 $\alpha$, releasing the transcriptionactivating form of ATF $6 \alpha$ that enters the nucleus and induces ER chaperon gene expression.

The activation of UPR pathways usually leads to the clearance of unfolded proteins and the restoration of ER homeostasis through reducing global protein synthesis and increasing chaperon protein expression. However, cell death occurs under prolonged or excessive ER stress when the ER protein load greatly exceeds its folding capacity (4). One of the UPR target genes encodes C/EBP homologous protein (CHOP)/growth arrest and DNA damageinducible gene 153 (GADD153) (5). As a transcription factor, CHOP activates pro-apoptotic gene expression encoding growth arrest and DNA damage-inducible 34 (GADD34), death receptor 5 (DR5), endoplasmic reticulum oxidoreductase-1 (Ero1 $\alpha$ ), and Bim (6). CHOP also represses anti-apoptotic gene $\mathrm{Bcl}-2$ expression (7). Other possible cell death pathways induced by ER stress include activation of apoptotic-signaling kinase-1 (ASK1) and p38 MAPK downstream of IRE1 $\alpha$ (6). Currently, one intriguing question that requires further investigation is what determines the pro-survival versus pro-death role of ER stress.

ER stress is involved in various diseases, ranging from cancer, diabetes, metabolic syndromes, to neurodegenerative diseases (8). Recently, the role of ER stress in hearing loss has attracted increasing research attention. Hearing loss (deafness) is the most prevalent sensory impairment in humans, affecting around 466 million worldwide (9). Both genetic and environmental factors contribute to hearing loss. Hereditary hearing loss is clinically divided into non-syndromic hearing loss and syndromic hearing loss, depending on the presence of other symptoms besides deafness. Mutations in more than 100 genes have been identified to be responsible for nonsyndromic hearing loss, and it is estimated that additional hundreds of genes are involved in hereditary hearing loss. Environmental factors, such as exposure to ototoxic chemicals, noise and ageing, lead to drug-induced hearing loss (DIHL), noise-induced hearing loss (NIHL) and agerelated hearing loss (ARHL), respectively. ARHL (also referred to as presbycusis) is especially important today, affecting nearly one-third of individuals over 65 years of age (9). In this review we will discuss the role of ER stress and its therapeutic potentials in both hereditary and acquired hearing loss.

\section{ER stress and hereditary hearing loss}

2.1 Wolfram syndrome 1 (WFS1)

WFS1, also called wolframin, is a transmembrane protein

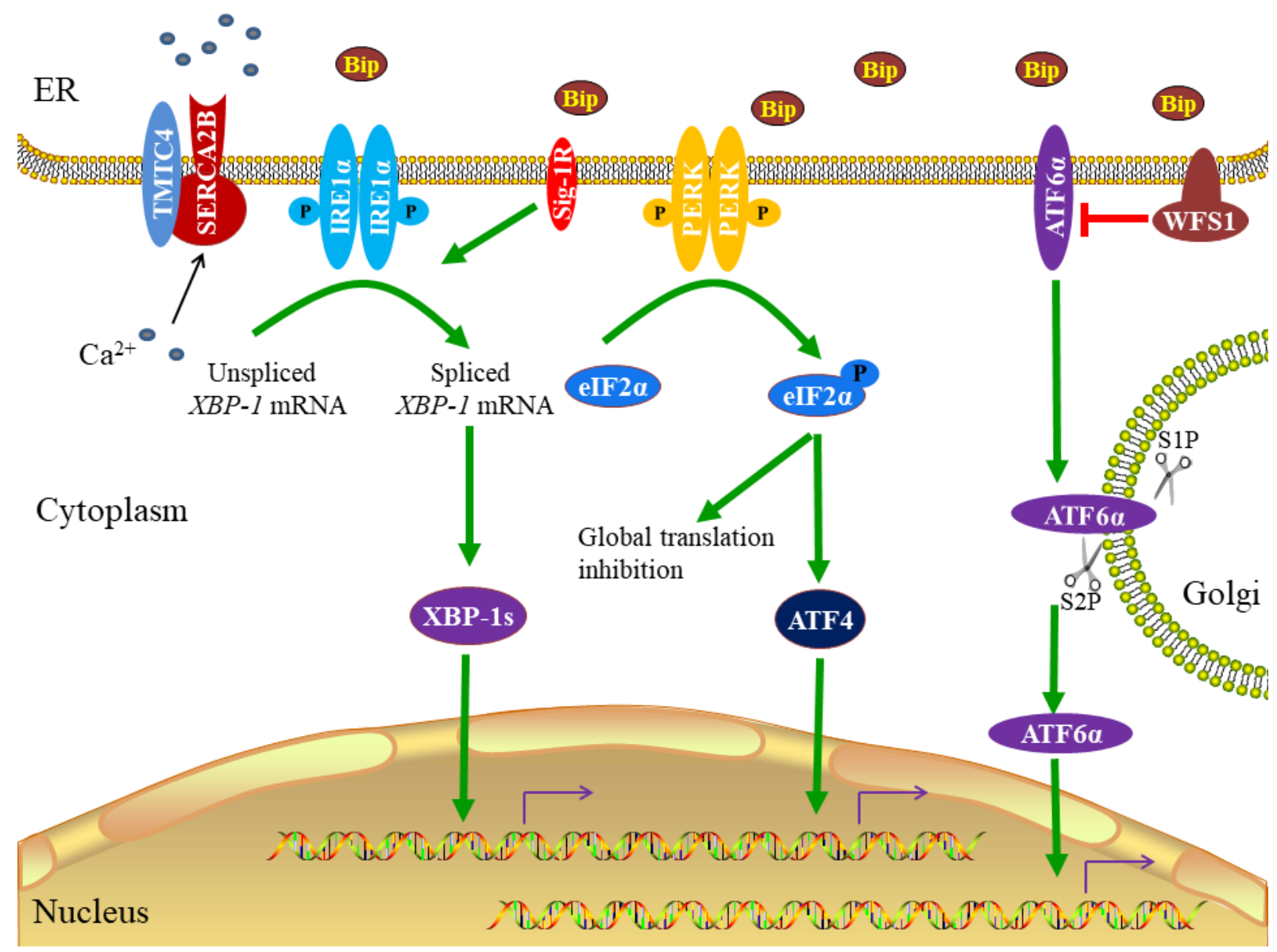

Figure 1. Endoplasmic reticulum (ER) stress and unfolded protein response (UPR) in mammals. See main text for details. 
that localizes on the ER membrane. WFS 1 interacts with the ER-localized vacuolar-type $\mathrm{H}^{+}$-ATPase V1A subunit (ATP6V1A), $\mathrm{Na}^{+} / \mathrm{K}^{+}$ATPase 1 subunit (ATP1B1), and calmodulin $(\mathrm{CaM})$, suggesting that it might play important roles in ER function and/or homeostasis (10-12). Under ER stress, IRE1 $\alpha$ and PERK pathways induce the expression of WFS1, which in turn recruits ATF6 $\alpha$ to E3 ligase HMG-CoA reductase degradation protein 1 (HRD1) for proteasomal degradation, therefore provides a negative feedback loop of UPR $(13,14)$.

Mutations in the WFS1 gene cause syndromic deafness Wolfram syndrome (WS) or non-syndromic deafness DFNA6/14/38 (15-18). WS is characterized by diabetes insipidus, diabetes mellitus, psychiatric illness, optic atrophy, and hearing loss, and is mostly caused by recessive WFS1 mutations $(15,16)$. In contrast, DFNA6/14/38 is caused by dominant WFS1 mutations (17, 18). In vitro studies showed that WS-associated WFS 1 dominant mutants induce constitutive ER stress $(19,20)$. Moreover, in $W f_{s} 1$ knockout mice or rats, elevated ER stress could be detected in pancreatic $\beta$-cells and retinal cells, consistent with its negative regulatory role in ER stress (21-24).

In the mouse inner ear, WFS1 is widely expressed in hair cells (HCs), spiral ganglion cells (SGCs), supporting cells (SCs), and stria vascularis marginal cells (25). Although $W f_{S} 1$ knockout mice or rats develop diabetes and optic atrophy, hearing phenotypes have not been reported in these animals. Recently, WFS1 expression was examined in the cochlea of marmoset (Callithrix jacchus), which is a nonhuman primate (26). The results showed that besides those cell types reported in the mouse study, WFS 1 immunoreactivity was also detected in the stria vascularis basal cells. The differential expression pattern of WFS1 might help to explain the different hearing phenotypes in WFS1 deficient rodents and primates. Development of primate models would be helpful for understanding the role of WFS1 in hearing and deafness.

A smaller portion of WS is caused by recessive mutations in the gene that encodes CDGSH iron-sulfur domain-containing protein 2 (CISD2) (27). CISD2, also named as ERIS or Miner1, is an integral membrane protein and localizes on the mitochondria-associated ER membranes (MAMs). Unlike WFS1, the function of CISD2 still remains poorly defined. Nevertheless, CISD2 has been suggested to regulate $\mathrm{Ca}^{2+}$ homeostasis and ER stress. Cisd $2^{-/}$mouse embryonic fibroblasts (MEFs) show dysregulated $\mathrm{Ca}^{2+}$ homeostasis and elevated ER stress (28). Similarly, fibroblasts from a WS patient with homozygous CISD2 mutation (Asn72Ser) show disturbed cellular $\mathrm{Ca}^{2+}$ homeostasis and expanded ER compartment, although no overt ER stress phenotype (29). Further investigations are warranted to understand the role of CISD2 in ER stress as well as hearing loss in more detail.

\subsection{Transmembrane and tetratricopeptide repeat containing 4 (TMTC4)}

TMTC4 is an ER transmembrane protein and is suggested to play important roles in regulating $\mathrm{Ca}^{2+}$ dynamics (30). TMTC4 interacts with the $\mathrm{Ca}^{2+}$ pump SERCA2B and is involved in maintaining the $\mathrm{Ca}^{2+}$ gradient between the cytoplasm and the ER. Inactivation of Tmtc4 in mice causes increased ER stress and UPR, possibly through dysregulation of ER $\mathrm{Ca}^{2+}$ level (30).

TMTC4 is expressed in the HCs and various SCs in the mouse cochlea (30). Mutation in the TMTC4 gene has not been associated with any diseases including hearing loss in human. However, Tmtc 4 knockout mice show progressive HC loss that leads to early onset hearing loss (30). Consistent with the proposed role of TMTC4 in $\mathrm{Ca}^{2+}$ homeostasis and ER stress, cochlear cells of Tmtc4 knockout mice show enhanced sensitivity to ERinduced apoptosis. In line with this, disruption of Chop gene partially improves the auditory function of Tmtc4 knockout mice (30).

\subsection{Cadherin 23 (CDH23)}

CDH23 is a large atypical cadherin, consisting of 27 extracellular cadherin repeats, a single transmembrane domain, and a short cytoplasmic part. CDH23 gene mutations cause syndromic hearing loss Usher syndrome (USH) 1D or non-syndromic hearing loss DFNB12 (31-33). USH is the most common inherited deaf-blindness, and so far ten genes have been associated with USH (34). These genes encode the so-called USH proteins, which bind to each other and play pivotal roles in the stereocilia and ribbon synapses of the $\mathrm{HCs}$.

Evidences suggest that before being transported to the plasma membrane, $\mathrm{CDH} 23$ is preassembled into a complex with other USH proteins harmonin and MYO7A at the ER in zebrafish HCs (35). Disruption of the complex induces ER stress characterized by expanded ER membrane and elevated BiP expression, which eventually leads to $\mathrm{HC}$ apoptosis (35). These results led to the hypothesis that USH proteins are transported from the ER to their destinations as a protein complex. When one USH protein is defective or missing, other complex components are exposed abnormally and recognized as misfolded proteins, hence triggering ER stress (35).

The involvement of deficient CDH23 in ER stress is further supported by a mutant Cdh23 mouse line erlong (erl) with a point mutation T208C. The erl mice suffer $\mathrm{HC}$ loss that eventually leads to early-onset progressive deafness (36). Further investigation showed that the mutant $\mathrm{CDH} 23$ failed to reach the stereocilia. Instead, it colocalized with BiP in the subapical regions of HCs (37). This may activate the PERK-eIF2 $\alpha$-ATF4-CHOP pathway, which eventually leads to $\mathrm{HC}$ apoptosis (37). Inactivation of the Chop gene, treatment with ER stress modulator salubrinal, chemical chaperone 4-phenylbutyrate (PBA) or tauroursodeoxycholic acid (TUDCA) preserves HCs and delays the progression of hearing loss in the erl mice (3739).

\subsection{Connexins}

Connexins are a family of membrane-spanning proteins, acting as the building blocks of gap junctions. By connecting the cytoplasm of adjacent animal cells, 
gap junctions provide direct intercellular communication for exchange of ions, metabolites, and second messengers. More than 20 mammalian connexin genes have been identified, whose mutations are responsible for various diseases such as peripheral neuropathy, skin disease, cataracts, and hearing loss (40).

In the cochlea, gap junctions are broadly present in the non-sensory cells including the SCs, the stria vascularis, the spiral limbus, and the spiral ligament (41). Mutations in the GJB2 gene that encodes connexin 26 (Cx26) are responsible for $\sim 50 \%$ of non-syndromic hearing loss $(42,43)$. Moreover, mutations in GJB6 (Cx30) and GJB3 $(\mathrm{Cx} 31)$ are also associated with non-syndromic hearing loss (44-46). Other deafness-related connexins include Cx29 (GJC3) and Cx43 (GJA1). Although mutations in GJC3 and GJA1 have not been clearly associated with hearing loss in humans, auditory function is affected in $C \times 29$ or $C \times 43$ mutant mice (47-49).

A possible link has been proposed connecting connexin expression and/or function with ER stress. Treating cultured mesangial cells with ER stress inducers leads to decreased Cx43 expression and reduced gap junctional intercellular communication (50). Therefore, gap junctions might protect cells under ER stress by preventing 'stress' signals from transmitting to adjacent cells (50). On the other hand, connexin gene mutations could induce ER stress. When overexpressed in cultured cells, several Cx26, Cx30 and Cx31 deafness-associated mutants are trapped in the ER instead of being localized on the plasma membrane (51-53). Moreover, Cx31R180X- and Cx31E183K-overexpressing cells show elevated BiP/ GRP78 expression, indicating elevated ER stress (51). However, ER stress is not elevated in cultured cells overexpressing deafness-associated Cx31 (66delD), suggesting that ER stress is not the sole underlying mechanism of mutant Cx31-associated cell death (54).

\subsection{Elongator acetyltransferase complex subunit 3 (ELP3)}

Elongator complex plays a pivotal role in regulating protein translation efficiency through modifying the wobble uridine (U34) in the anticodon of various tRNAs (55). This protein complex consists of two sets of six subunits ELP1-ELP6, among which ELP3 acts as the enzymatic core (56). Elongator-mediated tRNA modifications ensure fidelity and efficiency of protein translation, which are essential to normal proteostasis $(57,58)$. Elongator complex also plays important roles in $\alpha$-tubulin acetylation, transcriptional elongation, actin organization, kinase signaling, etc., and dysfunction of this complex is associated with various neurological diseases (59).

Conditional knockout of Elp3 gene in the cortical neurons decreases translation rates and activates the PERK-eIF $2 \alpha$-ATF4 pathway, eventually leading to microcephaly (60). In the cochlea, ELP3 is abundantly expressed in the SGNs and nascent HCs (61). Conditional knockout of Elp3 gene in the cochlea causes protein misfolding and aggregation, resulting in apoptosis of SGNs and defects in cochlear planar cell polarity (PCP), and eventually leading to severe hearing loss (61). Activation of ER stress was not examined in the cochlea of Elp3 knockout mice. Nevertheless, chemical chaperone PBA treatment alleviates protein aggregation and PCP deficits in Elp3 knockout mice, implying that ER stress is likely involved in ELP3-associated hearing loss (61).

\section{ER stress and acquired hearing loss \\ 3.1 ER stress and DIHL}

Ototoxic chemicals could lead to 'drug-induced' hearing loss (62). Studies in animals and cultured cells suggest that ER stress could be induced by ototoxic chemicals such as aminoglycosides, cisplatin, $\mathrm{N}$-acetyl-para-aminophenol (APAP), 3-nitropropionic acid (3-NP), and N-acetyl-pbenzoquinoneimine (NAPQI) (63-67). Additionally, ER stress activator tunicamycin treatment causes profound hearing loss in rats (68). Further investigations suggest that these chemicals affect different cell types in the cochlea. For example, aminoglycoside gentamicin induces ER stress in SGCs but not HCs, whereas tunicamycin induces ER stress in both HCs and SGCs $(65,68)$.

Calreticulin (CRT) is an ER-residing chaperone induced under ER stress (69). In the inner ear, CRT is expressed in the HCs and the strial marginal cells, and could bind aminoglycosides such as gentamicin (70), which inhibits the chaperon activity of CRT (71). Crt knockout or knockdown MEFs are more susceptible to gentamicin treatment, consistent with a protective role of CRT against gentamicin-induced cytotoxicity (70). CRT has been identified as one of the cisplatin-binding proteins in a screen, which also identified GRP78/BiP albeit at relatively low abundance (72). The significance of CRT and GRP78/BiP binding to gentamicin and cisplatin in hearing and deafness requires further investigation.

Consistent with the potential role of ER stress in DIHL, $\mathrm{Xbpl}^{+/-}$mice are more susceptible to aminoglycosideinduced hearing loss compared to wild-type mice (65). Furthermore, chemical chaperone TUDCA attenuates aminoglycoside-induced hearing loss in $\mathrm{Xbpl}^{+-}$mice (65). In addition, it was recently shown that TUDCA treatment also exerted a protective effect on cisplatin-induced hearing loss (66).

\subsection{ER stress and NIHL}

High-intensity noise could cause HCs and SGNs death, which eventually leads to the so-called NIHL (73). Expression levels of BiP/GRP78, XBP1s, CHOP/ GADD153, and caspase-3 are elevated in the cochlea of guinea pigs or mice during NIHL, suggesting that ER stress might play a role in this process $(30,74)$. Integrated stress response inhibitor (ISRIB) inhibits the PERKeIF $2 \alpha$-ATF4 pathway through activating the guanine nucleotide exchange factor (GEF) eIF2B $(75,76)$. Treatment of mice with ISRIB prior to noise exposure preserves HCs and improves hearing (30).

Sigma-1 receptor (Sig-1R) interacts with BiP at the MAMs, 
and regulates $\mathrm{Ca}^{2+}$ signaling and cell survival (77). Under ER stress, Sig-1R expression is increased via the PERKeIF2 $\alpha$-ATF4 pathway and inhibits cell apoptosis (78). Further investigations have shown that Sig-1R executes protective function through activating the IRE1 $\alpha$-XBP1 pathway and inhibiting CHOP expression $(79,80)$. Consistent with the protective role of Sig-1R in hearing loss, noise-induced cell death and hearing loss are significantly reduced in mice by treatment with Sig-1R agonist cutamesine (SA4503) (81).

Glucocorticoid-induced leucine zipper (GILZ) is a transcription factor that has been shown to protect cells from apoptosis (82-84). Under ER stress, overexpression of GILZ up-regulates BiP and down-regulates CHOP, ATF4, and XBP1s, and protects cells from apoptosis through a pathway involving mitochondrial function and oxidative phosphorylation (OXPHOS) (85). Recently, it was suggested that GILZ had similar protective effect in NIHL. Overexpression of GILZ protects rats from NIHL through increasing $\mathrm{BiP}$ and $\mathrm{Bcl}-\mathrm{xL}$, and decreasing $\mathrm{CHOP}$, Bax, and cleaved caspase-3, whereas GILZ silencing has the opposite effect (86).

\subsection{ER stress and ARHL}

ARHL, also called presbycusis, is more and more common nowadays, affecting nearly one-third of individuals over 65 years of age (9). There are evidences suggesting that ER stress is also involved in ARHL. For example, BiP/GRP78 expression is decreased, whereas CHOP expression is increased in the cochlea of aged mice (87). Consistently, cleaved caspase- 3 and caspase-9, but not caspase-12, are elevated in the cochlea of aged mice, indicating the activation of apoptosis (87).

Geranylgeranylacetone (GGA) is a nontoxic acyclic isoprenoid compound with protective function through increasing the expression of HSP70 (88). It has been shown that GGA treatment attenuates ARHL in mice (89). Moreover, GGA could ameliorate 3-NP-induced deafness as well as NIHL $(90,91)$. The protection of auditory function by GGA has been attributed to its activity as a HSP70 inducer. However, GGA could also induce BiP expression and enhance ER stress (92-94). The potential role of ER stress in GGA-mediated auditory protection awaits further examination.

\section{ER stress-based treatment of hearing loss}

Many small molecules are able to interfere with ER stress and provide protection for cells, while only a few of them have been tested in treatment of hearing loss. We will discuss these potential ER stress-based treatment of hearing loss in three categories: (1) restoring ER homeostasis; (2) modulating the PERK-eIF2 $\alpha$-ATF4 pathway; and (3) modulating the IRE1 $\alpha$-XBP1 pathway. As mentioned above, HSP70 inducer GGA could also induce BiP expression and enhance ER stress, and has been tested in hearing loss treatment in several animal experiments. At present, the specific target of GGA in ER stress remains elusive.

\subsection{Restoring ER homeostasis with chemical chaperones}

Chemical chaperones are small chemical compounds that could improve ER folding capacity and restore ER homeostasis, hence are extensively used to reduce ER stress. Unfolded or misfolded proteins are kept from aggregation by chemical chaperones through the interaction between the hydrophobic regions of each other (95). TUDCA and PBA are two most commonly used chemical chaperones. They could reduce aggregate accumulation and revert ER stress, and have been approved by the Food and Drug Administration (FDA) for clinical uses.

TUDCA is a taurine-conjugated derivative of ursodeoxycholic acid (UDCA), which used to be isolated from black bear gallbladders but can now be synthesized chemically. TUDCA has been widely used in experimental and clinical treatments of diabetes, liver disease, and neurodegenerative diseases (95). Recently, it was also tested in treatment of hearing loss. TUDCA treatment preserves HCs and delays the progression of hearing loss in Cdh23 mutant mice erl (38). Moreover, TUDCA treatment also shows protective effects against cisplatin- or aminoglycoside-induced hearing loss in rodents $(65,66,96)$.

First synthesized a century ago, PBA has been approved by the FDA in the treatment of urea cycle disease (97). Moreover, it has potential benefits for cancer, diabetes, thalassemia, cystic fibrosis, spinal muscular atrophy, and neurodegenerative diseases (95). PBA can also inhibit histone deacetylase (HDAC) and stimulate gene transcription. The protective effect of PBA on ER stress mainly involves its chaperone activity, given that removal of HDAC inhibitory activity does not affect its protective effect (98). Recently it was shown that PBA treatment preserved HCs and delayed hearing loss progression in Cdh23 mutant mice erl (39). The protective effect of PBA in hearing is further supported by a report showing that PBA could alleviate protein aggregation and hair cell deficits in Elp3 knockout mice (61).

\subsection{Modulating the PERK-eIF2 $\alpha$-ATF4 pathway}

ISRIB was identified as an inhibitor of PERK signaling in a cell-based screen (75). It was then shown that ISRIB inhibited the PERK-eIF2 $\alpha$-ATF4 pathway through activating the GEF eIF2B (76). ISRIB treatment shows protective effects in neurogenerative diseases $(99,100)$. Consistently, treatment with ISRIB preserves HCs and protects mice from NIHL (30). However, ISRIB treatment needs to be applied with caution. Besides inhibiting the PERK signaling, ISRIB could also inhibit stress granule (SG) formation induced by eIF2 $\alpha$ phosphorylation (101). It was recently reported that inhibition of SG formation by ISRIB increases $\mathrm{HC}$ death in cochlear explants during ototoxicity (102). The controversial effects of ISRIB on $\mathrm{HC}$ survival in these two studies require further investigation.

Salubrinal is a selective inhibitor of eIF $2 \alpha$ phosphatase complexes GADD34-PP1C, and could prevent ER stressinduced cell death $(103,104)$. However, its protective effect seems to be cell- and context-dependent. For 
example, salubrinal has been shown to enhance fatty acid-induced ER stress and increase rat pancreatic $\beta$-cell apoptosis (105). Salubrinal treatment preserves HCs and delays hearing loss progression in the erl mice, indicating a protective effect of salubrinal in hearing (37). Taken together, both PERK inhibitor ISRIB and PERK enhancer salubrinal show protective roles in treatment of hearing loss, suggesting that PERK signaling has a dual role in hearing that might be context-dependent.

\subsection{Modulating the IRE1 $\alpha-X B P 1$ pathway}

As mentioned above, Sig-1R is an important ER membrane protein that interacts with $\mathrm{BiP}$ at the MAMs and regulates $\mathrm{Ca}^{2+}$ signaling (77). Sig-1R stabilizes IRE1 $\alpha$ at the MAMs and prolongs IRE1 $\alpha$ 's activity under ER stress $(79,80)$. Sig-1R agonists have protective effects in various neurodegenerative diseases (106). Consistently, treatment of Sig-1R agonist SA4503 in mice significantly reduces noise-induced cell death and hearing loss, whereas shows no effect on ARHL (81).

\section{Perspectives}

ER stress has attracted more and more attentions in recent years. As discussed above, ER stress plays important roles in hearing loss, and could act as an effective target for deafness treatment (Table 1). Animal experiments showed that chemicals such as TUDCA, PBA, ISRIB, salubrinal, SA4503, and GGA have protective effects on both hereditary and acquired hearing loss through modulating ER stress. Meanwhile, deletion or overexpression of ER stress-related genes such as Chop and Gilz also show protective effect on hearing loss. These results suggest that ER stress could act as an effective and promising target for treatment of hearing loss.

However, ER stress-based treatment of hearing loss is still very limited at present. Among the small molecules that have been successfully used clinically or preclinically in treatments of diseases (such as neurodegenerative diseases), only a few have been tested in animal experiments for treatment of hearing loss. Many promising ER stress-related small molecules await further testing in deafness treatment in the future. Meanwhile, cautions must be taken because we now know that ER stress might play different roles in different types of hearing loss, and that the ER stress-targeted drugs might not be that specific. Moreover, ER stress play important roles in various cell types and organs, hence long-term administration of ER stress-targeted drugs might lead to serious adverse effects. Local drug delivery into the inner ear might help to solve the last problem.

Besides reducing side effects, local drug delivery can also help to bypass the blood labyrinth barrier (BLB) that prevents effective drug delivery into the inner ear by systemic administration. The abovementioned studies delivered drugs systematically via intraperitoneal injection, subcutaneous injection, or oral administration, which are less effective compared with local drug delivery. At present, two main local drug delivery routes are employed in the inner ear, which are intratympanic administration and intracochlear administration (107). In the less invasive intratympanic administration, a drug is delivered to the middle ear through the tympanic membrane, followed by diffusion into the inner ear through the round window. In the rather invasive intracochlear administration, a drug is applied directly to the cochlea, which is more efficient but has a significant risk of damaging the delicate cochlea. Further investigations are warranted to develop non-invasive or minimally invasive local delivery methods for deafness treatment (108). At present, local drug delivery is more frequently used in gene therapy, which is recently emerging as a promising alternative to small molecules in disease treatment.

Local delivery of viruses that encode XBP1s or BiP were shown to improve neuron survival in animal models of neurological diseases (109). Lentivirus-mediated

Table 1. Potential ER stress-base treatment of deafness.

\begin{tabular}{|c|c|c|c|}
\hline Deafness & Models & ER stress-related treatment & References \\
\hline DIHL & mice, rats, guinea pigs & GGA, TUDCA & $(65,66,90,96)$ \\
\hline \multirow[t]{2}{*}{$\mathrm{NIHL}$} & mice, guinea pigs & GGA, ISRIB, SA4503 & $(30,81,91)$ \\
\hline & rats & GILZ overexpression & $(86)$ \\
\hline ARHL & mice & GGA & (89) \\
\hline \multirow[t]{4}{*}{$\mathrm{HHL}$} & Cdh23 mutant mice (erl) & TUDCA, PBA, salubrinal & $(37-39)$ \\
\hline & Cdh23 mutant mice (erl) & Chop gene deletion & (37) \\
\hline & Tmtc4 ko mice & Chop gene deletion & $(30)$ \\
\hline & Elp3 cko mice & PBA & (61) \\
\hline
\end{tabular}


overexpression of GILZ has been shown to be protective in NIHL (86). However, the specific target cells of lentivirus are unclear in this study. Moreover, lentivirus has long-term safety concerns and is not commonly used in clinical trials (110). Recently, adeno-associated viruses (AAVs) become increasingly used in gene therapy because of its excellent safety and high efficiency (111). Several AAVs have been developed to efficiently deliver genes into HCs or SCs $(112,113)$. Hence it will be interesting to examine the therapeutic effect of AAV-mediated delivery of XBP1s, BiP, or GILZ into the cochlea.

As mentioned above, Chop gene deletion shows a protective effect in $C d h 23$ mutant mice and Tmtc4 knockout mice $(30,37)$. AAV-mediated RNA interference (RNAi) against dominant deafness-associated Tmcl mutation has been shown to improve HC survival and prevent hearing loss (114). It will be interesting to test whether AAV-mediated RNAi against CHOP also has a protective effect in hearing. As an attractive alternative to RNAi, CRISPR/Cas9-mediated genome editing has been employed to disrupt the dominant deafness-associated allele in the Tmc1 mutant mice (115). In that study, Cas9sgRNA complex was delivered via cationic lipid, which pointed out a new direction of developing a DNA- and virus-free treatment of hearing loss $(115,116)$.

\section{Funding body}

Our laboratory is supported by grants from the National Natural Science Foundation of China (81771001), Shandong Provincial Key Laboratory of Animal Cell and Developmental Biology (SPKLACDB-2019000), and the Fundamental Research Funds of Shandong University (2018JC025).

\section{Conflict of interest}

The authors declare that they have no conflict of interest.

\section{References}

1. Lee AS. The ER chaperone and signaling regulator GRP78/ $\mathrm{BiP}$ as a monitor of endoplasmic reticulum stress. Methods. 2005;35(4):373-81.

2. Bernasconi R, Molinari M. ERAD and ERAD tuning: Disposal of cargo and of ERAD regulators from the mammalian ER. Curr Opin Cell Biol. 2011;23(2):176-83.

3. Mori K. Tripartite management of unfolded proteins in the endoplasmic reticulum. Cell. 2000;101(5):451-4.

4. Iurlaro R, Munoz-Pinedo C. Cell death induced by endoplasmic reticulum stress. FEBS J. 2016;283(14):2640-52.

5. Oyadomari S, Mori M. Roles of CHOP/GADD153 in endoplasmic reticulum stress. Cell Death Differ. 2004;11(4):381-9.

6. Sano R, Reed JC. ER stress-induced cell death mechanisms Biochim Biophys Acta. 2013;1833(12):3460-70.

7. McCullough KD, Martindale JL, Klotz LO, Aw TY, Holbrook NJ. Gadd153 sensitizes cells to endoplasmic reticulum stress by down-regulating $\mathrm{Bcl} 2$ and perturbing the cellular redox state. Mol Cell Biol. 2001;21(4):1249-59.

8. Kaneko M, Imaizumi K, Saito A, Kanemoto S, Asada R, Matsuhisa K, et al. ER stress and disease: toward prevention and treatment. Biol Pharm Bull. 2017;40(9):1337-43.

9. Global estimates on prevalence of hearing loss. Geneva: World Health Organization; 2018. Available from: http:// wwwwhoint/pbd/deafness/estimates/en/ [cited 2018 Jan 27].

10. Zatyka M, Ricketts C, da Silva Xavier G, Minton J, Fenton $\mathrm{S}$, Hofmann-Thiel $\mathrm{S}$, et al. Sodium-potassium ATPase 1 subunit is a molecular partner of Wolframin, an endoplasmic reticulum protein involved in ER stress. Hum Mol Genet. 2008;17(2):190-200.

11. Yurimoto S, Hatano N, Tsuchiya M, Kato K, Fujimoto $\mathrm{T}$, Masaki T, et al. Identification and characterization of wolframin, the product of the wolfram syndrome gene (WFS1), as a novel calmodulin-binding protein. Biochemistry. 2009;48(18):3946-55.

12. Gharanei S, Zatyka M, Astuti D, Fenton J, Sik A, Nagy Z, et al. Vacuolar-type H+-ATPase V1A subunit is a molecular partner of Wolfram syndrome 1 (WFS1) protein, which regulates its expression and stability. Hum Mol Genet. 2013;22(2):203-17.

13. Fonseca SG, Fukuma M, Lipson KL, Nguyen LX, Allen JR, Oka Y, et al. WFS1 is a novel component of the unfolded protein response and maintains homeostasis of the endoplasmic reticulum in pancreatic beta-cells. J Biol Chem. 2005;280(47):39609-15

14. Fonseca SG, Ishigaki S, Oslowski CM, Lu S, Lipson KL, Ghosh R, et al. Wolfram syndrome 1 gene negatively regulates ER stress signaling in rodent and human cells. J Clin Investig. 2010;120(3):744-55.

15. Inoue $\mathrm{H}$, Tanizawa $\mathrm{Y}$, Wasson J, Behn $\mathrm{P}$, Kalidas $\mathrm{K}$, BernalMizrachi $\mathrm{E}$, et al. A gene encoding a transmembrane protein is mutated in patients with diabetes mellitus and optic atrophy (Wolfram syndrome). Nat Genet. 1998;20(2):143-8.

16. Strom TM, Hortnagel K, Hofmann S, Gekeler F, Scharfe C, Rabl W, et al. Diabetes insipidus, diabetes mellitus, optic atrophy and deafness (DIDMOAD) caused by mutations in a novel gene (wolframin) coding for a predicted transmembrane protein. Hum Mol Genet. 1998;7(13):2021-8.

17. Bespalova IN, Van Camp G, Bom SJ, Brown DJ, Cryns K, DeWan AT, et al. Mutations in the Wolfram syndrome 1 gene (WFS1) are a common cause of low frequency sensorineural hearing loss. Hum Mol Genet. 2001;10(22):2501-8.

18. Young TL, Ives E, Lynch E, Person R, Snook S, MacLaren L, et al. Non-syndromic progressive hearing loss DFNA38 is caused by heterozygous missense mutation in the Wolfram syndrome gene WFS1. Hum Mol Genet. 2001;10(22):2509-14.

19. De Franco E, Flanagan SE, Yagi T, Abreu D, Mahadevan $\mathrm{J}$, Johnson MB, et al. Dominant ER stress-inducing WFS1 mutations underlie a genetic syndrome of neonatal/infancyonset diabetes, congenital sensorineural deafness, and congenital cataracts. Diabetes. 2017;66(7):2044-53.

20. Morikawa S, Tajima T, Nakamura A, Ishizu K, Ariga T. A novel heterozygous mutation of the WFS1 gene leading to constitutive endoplasmic reticulum stress is the cause of Wolfram syndrome. Pediatr Diabetes. 2017;18(8):934-41.

21. Ishihara H, Takeda S, Tamura A, Takahashi R, Yamaguchi $S$, Takei $D$, et al. Disruption of the WFS1 gene in mice causes progressive beta-cell loss and impaired stimulussecretion coupling in insulin secretion. Hum Mol Genet. 2004;13(11):1159-70.

22. Yamada $\mathrm{T}$, Ishihara H, Tamura A, Takahashi R, Yamaguchi S, Takei D, et al. WFS1-deficiency increases endoplasmic reticulum stress, impairs cell cycle progression and triggers the apoptotic pathway specifically in pancreatic beta-cells. Hum Mol Genet. 2006;15(10):1600-9.

23. Bonnet Wersinger D, Benkafadar N, Jagodzinska J, Hamel C, Tanizawa Y, Lenaers G, et al. Impairment of visual function and retinal ER stress activation in Wfs1-deficient mice. PLoS One. 2014;9(5):e97222.

24. Plaas M, Seppa K, Reimets R, Jagomae T, Toots M, Koppel $\mathrm{T}$, et al. Wfs 1 - deficient rats develop primary symptoms of Wolfram syndrome: insulin-dependent diabetes, optic nerve atrophy and medullary degeneration. Sci Rep. 2017;7(1):10220.

25. Cryns K, Thys S, Van Laer L, Oka Y, Pfister M, Van Nassauw L, et al. The WFS1 gene, responsible for low frequencysensorineural hearing loss and Wolfram syndrome, is expressed in a variety of inner ear cells. Histochem Cell 
Biol. 2003;119(3):247-56.

26. Suzuki N, Hosoya M, Oishi N, Okano H, Fujioka M, Ogawa K. Expression pattern of wolframin, the WFS1 (Wolfram syndrome-1 gene) product, in common marmoset (Callithrix jacchus) cochlea. Neuroreport. 2016;27(11):833-6.

27. Amr S, Heisey C, Zhang M, Xia XJ, Shows KH, Ajlouni K, et al. A homozygous mutation in a novel zinc-finger protein, ERIS, is responsible for Wolfram syndrome 2. Am J Hum Genet. 2007;81(4):673-83.

28. Wiley SE, Andreyev AY, Divakaruni AS, Karisch R, Perkins G, Wall EA, et al. Wolfram Syndrome protein, Miner1, regulates sulphydryl redox status, the unfolded protein response, and $\mathrm{Ca}^{2+}$ homeostasis. EMBO Mol Med. 2013;5(6):904-18.

29. Rouzier C, Moore D, Delorme C, Lacas-Gervais S, AitEl-Mkadem S, Fragaki K, et al. A novel CISD2 mutation associated with a classical Wolfram syndrome phenotype alters $\mathrm{Ca}^{2+}$ homeostasis and ER-mitochondria interactions. Hum Mol Genet. 2017;26(9):1599-611.

30. Li J, Akil O, Rouse SL, McLaughlin CW, Matthews IR, Lustig LR, et al. Deletion of Tmtc4 activates the unfolded protein response and causes postnatal hearing loss. J Clin Investig. 2018;128(11):5150-62.

31. Bork JM, Peters LM, Riazuddin S, Bernstein SL, Ahmed ZM, Ness SL, et al. Usher syndrome 1D and nonsyndromic autosomal recessive deafness DFNB12 are caused by allelic mutations of the novel cadherin-like gene $\mathrm{CDH} 23$. Am J Hum Genet. 2001;68(1):26-37.

32. Di Palma F, Holme RH, Bryda EC, Belyantseva IA, Pellegrino R, Kachar B, et al. Mutations in Cdh23, encoding a new type of cadherin, cause stereocilia disorganization in waltzer, the mouse model for Usher syndrome type 1D. Nature Genetics. 2001;27(1):103-7.

33. Bolz H, von Brederlow B, Ramirez A, Bryda EC, Kutsche $\mathrm{K}$, Nothwang HG, et al. Mutation of $\mathrm{CDH} 23$, encoding a new member of the cadherin gene family, causes Usher syndrome type 1D. Nat Genet. 2001;27(1):108-12.

34. Mathur P, Yang J. Usher syndrome: Hearing loss, retina degeneration and associated abnormalities. Biochim Biophys Acta. 2015;1852(3):406-20.

35. Blanco-Sanchez B, Clement A, Fierro J, Jr., Washbourne P, Westerfield M. Complexes of Usher proteins preassemble at the endoplasmic reticulum and are required for trafficking and ER homeostasis. Dis Model Mech. 2014;7(5):547-59.

36. Han F, Yu H, Tian C, Chen HE, Benedict-Alderfer C, Zheng $\mathrm{Y}$, et al. A new mouse mutant of the Cdh23 gene with earlyonset hearing loss facilitates evaluation of otoprotection drugs. Pharmacogenomics J. 2012;12(1):30-44.

37. Hu J, Li B, Apisa L, Yu H, Entenman S, Xu M, et al. ER stress inhibitor attenuates hearing loss and hair cell death in Cdh23erl/erl mutant mice. Cell Death Dis. 2016;7(11):e2485.

38. $\mathrm{Hu} \mathrm{J}, \mathrm{Xu} \mathrm{M}$, Yuan J, Li B, Entenman S, Yu H, et al. Tauroursodeoxycholic acid prevents hearing loss and hair cell death in Cdh23 $3^{\text {er/erl }}$ mice. Neuroscience. 2016;316:311-20.

39. Li B, Zheng T, Yan C, Wang W, Zhang J, Zhang L, et al. Chemical chaperone 4-phenylbutyrate prevents hearing loss and cochlear hair cell death in $\mathrm{Cdh} 23^{\text {erlerl }}$ mutant mice. Neuroreport. 2019;30(3):145-50.

40. Srinivas M, Verselis VK, White TW. Human diseases associated with connexin mutations. Biochim Biophys Acta. 2018;1860(1):192-201.

41. Wingard JC, Zhao HB. Cellular and deafness mechanisms underlying connexin mutation-induced hearing loss A common hereditary deafness. Frontiers in Cellular Neuroscience. 2015:9:202.

42. Kelsell DP, Dunlop J, Stevens HP, Lench NJ, Liang JN, Parry $\mathrm{G}$, et al. Connexin 26 mutations in hereditary non-syndromic sensorineural deafness. Nature. 1997;387(6628):80-3.

43. Zelante L, Gasparini P, Estivill X, Melchionda S, D'Agruma L, Govea N, et al. Connexin26 mutations associated with the most common form of non-syndromic neurosensory autosomal recessive deafness (DFNB1) in Mediterraneans.
Hum Mol Genet. 1997;6(9):1605-9

44. Grifa A, Wagner CA, D'Ambrosio L, Melchionda S, Bernardi F, Lopez-Bigas N, et al. Mutations in GJB6 cause nonsyndromic autosomal dominant deafness at DFNA3 locus. Nat Genet. 1999;23(1):16-8.

45. Liu XZ, Xia XJ, Xu LR, Pandya A, Liang CY, Blanton SH, et al. Mutations in connexin31 underlie recessive as well as dominant non-syndromic hearing loss. Hum Mol Genet. 2000;9(1):63-7.

46. del Castillo I, Villamar M, Moreno-Pelayo MA, del Castillo FJ, Alvarez A, Telleria D, et al. A deletion involving the connexin 30 gene in nonsyndromic hearing impairment. NEJM. 2002;346(4):243-9.

47. Tang W, Zhang Y, Chang Q, Ahmad S, Dahlke I, Yi H, et al. Connexin29 is highly expressed in cochlear Schwann cells, and it is required for the normal development and function of the auditory nerve of mice. J Neurosci. 2006;26(7):1991-9.

48. Kim AH, Nahm E, Sollas A, Mattiace L, Rozental R. Connexin 43 and hearing: possible implications for retrocochlear auditory processing. Laryngoscope. 2013;123(12):3185-93.

49. Abitbol JM, Kelly JJ, Barr KJ, Allman BL, Laird DW. Mice harbouring an oculodentodigital dysplasia-linked $\mathrm{C} \times 43$ G60S mutation have severe hearing loss. J Cell Sci. 2018;131(9):jcs214635.

50. Huang $T$, Wan $Y$, Zhu Y, Fang $X$, Hiramatsu N, Hayakawa $\mathrm{K}$, et al. Downregulation of gap junction expression and function by endoplasmic reticulum stress. J Biol Chem. 2009;107(5):973-83.

51. Xia $\mathrm{K}, \mathrm{Ma} \mathrm{H}$, Xiong $\mathrm{H}$, Pan $\mathrm{Q}$, Huang $\mathrm{L}$, Wang $\mathrm{D}$, et al. Trafficking abnormality and ER stress underlie functional deficiency of hearing impairment-associated connexin-31 mutants. Protein Cell. 2010;1(10):935-43.

52. Zhang Y, Wang J, Li L, Sun Y, Feng B. Three common GJB2 mutations causing nonsyndromic hearing loss in Chinese populations are retained in the endoplasmic reticulum. Acta Oto-Laryngologica. 2010;130(7):799-803.

53. Berger AC, Kelly JJ, Lajoie P, Shao Q, Laird DW. Mutations in Cx30 that are linked to skin disease and non-syndromic hearing loss exhibit several distinct cellular pathologies. J Cell Sci. 2014;127(Pt 8):1751-64.

54. Tattersall D, Scott CA, Gray C, Zicha D, Kelsell DP. EKV mutant connexin 31 associated cell death is mediated by ER stress. Hum Mol Genet. 2009;18(24):4734-45.

55. Huang B, Johansson MJ, Bystrom AS. An early step in wobble uridine tRNA modification requires the Elongator complex. RNA. 2005;11(4):424-36.

56. Wittschieben BO, Otero G, de Bizemont T, Fellows J, Erdjument-Bromage $\mathrm{H}$, Ohba $\mathrm{R}$, et al. A novel histone acetyltransferase is an integral subunit of elongating RNA polymerase II holoenzyme. Mol Cell. 1999;4(1):123-8.

57. Johansson MJ, Esberg A, Huang B, Bjork GR, Bystrom AS. Eukaryotic wobble uridine modifications promote a functionally redundant decoding system. Mol Cell Bio. 2008;28(10):3301-12.

58. Nedialkova DD, Leidel SA. Optimization of codon translation rates via tRNA modifications maintains proteome integrity. Cell. 2015;161(7):1606-18.

59. Kojic M, Wainwright $B$. The many faces of Elongator in neurodevelopment and disease. Front Mol Neurosci. 2016;9:115.

60. Laguesse S, Creppe C, Nedialkova DD, Prevot PP, Borgs $L$, Huysseune $S$, et al. A dynamic unfolded protein response contributes to the control of cortical neurogenesis. Dev Cell. 2015;35(5):553-67.

61. Freeman S, Mateo Sanchez S, Pouyo R, Van Lerberghe PB, Hanon K, Thelen N, et al. Proteostasis is essential during cochlear development for neuron survival and hair cell polarity. EMBO Rep. 2019;20(9):e47097.

62. Lanvers-Kaminsky C, Zehnhoff-Dinnesen AA, Parfitt R, Ciarimboli G. Drug-induced ototoxicity: mechanisms, 
pharmacogenetics, and protective strategies. Clin Pharmaco Ther. 2017;101(4):491-500.

63. Fujinami Y, Mutai H, Kamiya K, Mizutari K, Fujii M, Matsunaga T. Enhanced expression of C/EBP homologous protein $(\mathrm{CHOP})$ precedes degeneration of fibrocytes in the lateral wall after acute cochlear mitochondrial dysfunction induced by 3-nitropropionic acid. Neurochem Int 2010;56(3):487-94.

64. Kalinec GM, Thein P, Parsa A, Yorgason J, Luxford W, Urrutia R, et al. Acetaminophen and NAPQI are toxic to auditory cells via oxidative and endoplasmic reticulum stress-dependent pathways. Hearing Res. 2014;313:26-37.

65. Oishi N, Duscha S, Boukari H, Meyer M, Xie J, Wei G, et al. XBP1 mitigates aminoglycoside-induced endoplasmic reticulum stress and neuronal cell death. Cell Death Dis. 2015;6:e1763.

66. Zong S, Liu T, Wan F, Chen P, Luo P, Xiao H. Endoplasmic reticulum stress is involved in cochlear cell apoptosis in a cisplatin-induced ototoxicity rat model. Audiol Neuro-Otol. 2017;22(3):160-8

67. Tu Y, Fan G, Sun H, Cai X, Kong W. Endoplasmic reticulum stress is involved in spiral ganglion neuron apoptosis following chronic kanamycin-induced deafness. Biosci Rep. 2019;39(2):BSR20181749.

68. Fujinami $\mathrm{Y}$, Mutai $\mathrm{H}$, Mizutari $\mathrm{K}$, Nakagawa S, Matsunaga T. A novel animal model of hearing loss caused by acute endoplasmic reticulum stress in the cochlea. J Pharmacol Sci. 2012;118(3):363-72.

69. Yang Y, Ma F, Liu Z, Su Q, Liu Y, Liu Z, et al. The ERlocalized $\mathrm{Ca}^{2+}$-binding protein calreticulin couples $\mathrm{ER}$ stress to autophagy by associating with microtubule-associated protein 1A/1B light chain 3. J Biol Chem. 2019;294(3):772-82.

70. Karasawa T, Wang Q, David LL, Steyger PS. Calreticulin binds to gentamicin and reduces drug-induced ototoxicity. Toxicol Sci. 2011;124(2):378-87.

71. Horibe T, Matsui H, Tanaka M, Nagai H, Yamaguchi $Y$, Kato $\mathrm{K}$, et al. Gentamicin binds to the lectin site of calreticulin and inhibits its chaperone activity. Biochem Biophys Res Commun. 2004;323(1):281-7.

72. Karasawa T, Sibrian-Vazquez M, Strongin RM, Steyger PS. Identification of cisplatin-binding proteins using agarose conjugates of platinum compounds. PLoS One. 2013;8(6):e66220.

73. Liberman MC. Noise-induced hearing loss: Permanent versus temporary threshold shifts and the effects of hair cell versus neuronal degeneration. Adv Exp Med Biol. 2016;875:1-7.

74. Xue Q, Li C, Chen J, Guo H, Li D, Wu X. The Protective effect of the endoplasmic reticulum stress-related factors BiP/GRP78 and CHOP/Gadd153 on noise-induced hearing loss in guinea pigs. Noise Health. 2016;18(84):247-55.

75. Sidrauski C, Acosta-Alvear D, Khoutorsky A, Vedantham $\mathrm{P}$, Hearn BR, Li H, et al. Pharmacological brake-release of mRNA translation enhances cognitive memory. eLife. 2013;2:e00498.

76. Sidrauski C, Tsai JC, Kampmann M, Hearn BR, Vedantham $P$, Jaishankar $P$, et al. Pharmacological dimerization and activation of the exchange factor elF2B antagonizes the integrated stress response. eLife. 2015;4:e07314.

77. Hayashi T, Su TP. Sigma-1 receptor chaperones at the ERmitochondrion interface regulate $\mathrm{Ca}^{2+}$ signaling and cell survival. Cell. 2007;131(3):596-610.

78. Mitsuda T, Omi T, Tanimukai H, Sakagami $Y$, Tagami $S$, Okochi M, et al. Sigma-1Rs are upregulated via PERK/elF2alpha/ATF4 pathway and execute protective function in ER stress. Biochem Biophys Res Commun 2011;415(3):519-25.

79. Mori T, Hayashi T, Hayashi E, Su TP. Sigma-1 receptor chaperone at the ER-mitochondrion interface mediates the mitochondrion-ER-nucleus signaling for cellular survival. PLoS One. 2013;8(10):e76941.
80. Alam S, Abdullah CS, Aishwarya R, Orr AW, Traylor J, Miriyala $S$, et al. Sigmar1 regulates endoplasmic reticulum stress-induced C/EBP-homologous protein expression in cardiomyocytes. Biosci Rep. 2017;37(4):BSR20170898.

81. Yamashita D, Sun GW, Cui Y, Mita S, Otsuki N, Kanzaki S, et al. Neuroprotective effects of cutamesine, a ligand of the sigma-1 receptor chaperone, against noise-induced hearing loss. J Neurosci Res. 2015;93(5):788-95.

82. D'Adamio F, Zollo O, Moraca R, Ayroldi E, Bruscoli S, Bartoli $A$, et al. A new dexamethasone-induced gene of the leucine zipper family protects T lymphocytes from TCR/CD3activated cell death. Immunity. 1997;7(6):803-12.

83. Asselin-Labat ML, David M, Biola-Vidamment A, Lecoeuche D, Zennaro MC, Bertoglio J, et al. GILZ, a new target for the transcription factor FoxO3, protects $\mathrm{T}$ lymphocytes from interleukin-2 withdrawal-induced apoptosis. Blood. 2004;104(1):215-23.

84. Delfino DV, Agostini M, Spinicelli S, Vito P, Riccardi C. Decrease of $\mathrm{Bcl}-\mathrm{xL}$ and augmentation of thymocyte apoptosis in GILZ overexpressing transgenic mice. Blood. 2004;104(13):4134-41.

85. Andre F, Corazao-Rozas P, Idziorek T, Quesnel B, Kluza J, Marchetti P. GILZ overexpression attenuates endoplasmic reticulum stress-mediated cell death via the activation of mitochondrial oxidative phosphorylation. Biochem Biophys Res Commun. 2016;478(2):513-20.

86. Jia H, Yu Z, Ge X, Chen Z, Huang X, Wei Y. Glucocorticoidinduced leucine zipper protects noise-induced apoptosis in cochlear cells by inhibiting endoplasmic reticulum stress in rats. Med Mol Morphol. 2019; doi: 10.1007/s00795-01900232-7. [Epub ahead of print]

87. Wang W, Sun Y, Chen S, Zhou X, Wu X, Kong W, et al. Impaired unfolded protein response in the degeneration of cochlea cells in a mouse model of age-related hearing loss. Exp Gerontol. 2015;70:61-70.

88. Patury S, Miyata Y, Gestwicki JE. Pharmacological targeting of the Hsp70 chaperone. Curr Top Med Chem. 2009;9(15):1337-51.

89. Mikuriya T, Sugahara K, Sugimoto K, Fujimoto M, Takemoto $\mathrm{T}$, Hashimoto $\mathrm{M}$, et al. Attenuation of progressive hearing loss in a model of age-related hearing loss by a heat shock protein inducer, geranylgeranylacetone. Brain Res. 2008;1212:9-17

90. Kim YH, Song JJ, Kim YC, Park KT, Lee JH, Choi JM, et al. Geranylgeranylacetone ameliorates acute cochlear damage caused by 3-nitropropionic acid. Neurotoxicology. 2010;31(3):317-25.

91. Mikuriya T, Sugahara K, Takemoto T, Tanaka K, Takeno K, Shimogori $\mathrm{H}$, et al. Geranylgeranylacetone, a heat shock protein inducer, prevents acoustic injury in the guinea pig. Brain Res. 2005;1065(1-2):107-14.

92. Endo S, Hiramatsu N, Hayakawa K, Okamura M, Kasai A Tagawa $Y$, et al. Geranylgeranylacetone, an inducer of the 70-kDa heat shock protein (HSP70), elicits unfolded protein response and coordinates cellular fate independently of HSP70. Mol Pharmacol. 2007;72(5):1337-48.

93. Hayakawa K, Hiramatsu N, Okamura M, Yao J, Paton AW, Paton JC, et al. Blunted activation of NF-kappaB and NF-kappaB-dependent gene expression by geranylgeranylacetone: involvement of unfolded protein response. Biochem Biophys Res Commun. 2008;365(1):47-53.

94. Kanemura H, Kusumoto K, Miyake H, Tashiro S, Rokutan K, Shimada M. Geranylgeranylacetone prevents acute liver damage after massive hepatectomy in rats through suppression of a CXC chemokine GRO1 and induction of heat shock proteins. J Gastrointest Surg. 2009;13(1):66-73.

95. Cortez L, Sim V. The therapeutic potential of chemical chaperones in protein folding diseases. Prion. 2014;8(2):28938.

96. Jia Z, He Q, Shan C, Li F. Tauroursodeoxycholic acidattenuates gentamicin-induced cochlear hair cell death in vitro. Toxicol Lett. 2018;294:20-6. 
97. Brusilow SW, Maestri NE. Urea cycle disorders: diagnosis, pathophysiology, and therapy. Adv Pediatr. 1996;43:127-70.

98. Mimori S, Ohtaka H, Koshikawa Y, Kawada K, Kaneko $\mathrm{M}$, Okuma $\mathrm{Y}$, et al. 4-Phenylbutyric acid protects against neuronal cell death by primarily acting as a chemica chaperone rather than histone deacetylase inhibitor. Bioorganic Med Chem Lett. 2013;23(21):6015-8.

99. Halliday M, Radford H, Sekine $\mathrm{Y}$, Moreno J, Verity N, le Quesne J, et al. Partial restoration of protein synthesis rates by the small molecule ISRIB prevents neurodegeneration without pancreatic toxicity. Cell Death Dis. 2015;6:e1672.

100. Hosoi T, Kakimoto M, Tanaka K, Nomura J, Ozawa K. Unique pharmacological property of ISRIB in inhibition of $A \beta$-induced neuronal cell death. J Pharmacol Sci. 2016;131(4):292-5.

101. Sidrauski C, McGeachy AM, Ingolia NT, Walter P. The small molecule ISRIB reverses the effects of elF2a phosphorylation on translation and stress granule assembly. eLife. 2015;4:05033.

102. Goncalves AC, Towers ER, Haq N, Porco JA, Jr., Pelletier J, Dawson SJ, et al. Drug-induced stress granule formation protects sensory hair cells in mouse cochlear explants during ototoxicity. Sci Rep. 2019;9(1):12501.

103. Boyce M, Bryant KF, Jousse C, Long K, Harding HP, Scheuner $D$, et al. A selective inhibitor of elF2alpha dephosphorylation protects cells from ER stress. Science. 2005;307(5711):935-9.

104. Sokka AL, Putkonen N, Mudo G, Pryazhnikov E, Reijonen $\mathrm{S}$, Khiroug $\mathrm{L}$, et al. Endoplasmic reticulum stress inhibition protects against excitotoxic neuronal injury in the rat brain. $J$ Neurosci. 2007;27(4):901-8.

105. Cnop M, Ladriere L, Hekerman P, Ortis F, Cardozo AK, Dogusan Z, et al. Selective inhibition of eukaryotic translation initiation factor 2 alpha dephosphorylation potentiates fatty acid-induced endoplasmic reticulum stress and causes pancreatic beta-cell dysfunction and apoptosis. J Biol Chem. 2007;282(6):3989-97.
106. Ryskamp DA, Korban S, Zhemkov V, Kraskovskaya N, Bezprozvanny I. Neuronal sigma-1 receptors: Signaling functions and protective roles in neurodegenerative diseases. Front Neurosci. 2019;13:862.

107. El Kechai N, Agnely F, Mamelle E, Nguyen Y, Ferrary E, Bochot A. Recent advances in local drug delivery to the inner ear. Int J Pharm. 2015;494(1):83-101.

108. Hao J, Li SK. Inner ear drug delivery: Recent advances, challenges, and perspective. Eur J Pharm Sci. 2019;126:82-92.

109. Valenzuela V, Martinez G, Duran-Aniotz C, Hetz C. Gene therapy to target ER stress in brain diseases. Brain Res. 2016;1648(Pt B):561-70.

110. Sacheli R, Delacroix L, Vandenackerveken $P$, Nguyen $L$, Malgrange $B$. Gene transfer in inner ear cells: a challenging race. Gene Ther. 2013;20(3):237-47.

111. Colella P, Ronzitti G, Mingozzi F. Emerging issues in AAVmediated in vivo gene therapy. Mol Ther Methods Clin Dev. 2018;8:87-104.

112. Landegger LD, Pan B, Askew C, Wassmer SJ, Gluck SD, Galvin A, et al. A synthetic AAV vector enables safe and efficient gene transfer to the mammalian inner ear. Nat Biotechnol. 2017;35(3):280-4

113. Tan F, Chu C, Qi J, Li W, You D, Li K, et al. AAV-ie enables safe and efficient gene transfer to inner ear cells. Nat Commun. 2019;10(1):3733

114. Shibata SB, Ranum PT, Moteki H, Pan B, Goodwin AT, Goodman SS, et al. RNA interference prevents autosomaldominant hearing loss. Am J Hum Genet. 2016;98(6):1101-13.

115. Gao X, Tao Y, Lamas V, Huang M, Yeh WH, Pan B, et al. Treatment of autosomal dominant hearing loss by in vivo delivery of genome editing agents. Nature. 2018;553(7687):217-21.

116. Zuris JA, Thompson DB, Shu Y, Guilinger JP, Bessen JL, Hu $\mathrm{JH}$, et al. Cationic lipid-mediated delivery of proteins enables efficient protein-based genome editing in vitro and in vivo. Nat Biotechnol. 2015;33(1):73-80. 